\title{
A glimmer of hope in American pain medicine?
}

\section{Michael E Schatman}

US Pain Foundation, Bellevue, WA, USA
Correspondence: Michael E Schatman US Pain Foundation - Research Division, I I9| I NE | ${ }^{\text {st }}$ Street, Suite 208, Bellevue, WA, USA 98005

Email headdock@comcast.net
This article was published in the following Dove Press journal:

Journal of Pain Research

13 July 2016

Number of times this article has been viewed

Over the past 8 years, I have acquired a degree of notoriety relating to my scathing criticism of the badly broken American pain care system. In the three-part series on the crisis in pain care in the United States that I coauthored with Dr Jim Giordano in $2008,{ }^{1-3}$ we performed an ethical analysis of our system, examining the need for a paradigmatic revision if we were to adequately treat a disease as complex as is chronic pain, given the system's economic realities. Due to the insurance and hospital industries' adherence to the "business ethic" of cost-containment and profitability (as opposed to patient well-being), we were witnessing the profound undertreatment of pain in conjunction with a growing reliance upon technophilism, ie, an emphasis on technologically driven pain care sorely lacking a reasonable evidence-basis. Early in the following decade, Dr Alan Lebovits and I guest-edited a special series in Pain Medicine on the unfortunate devolution of the "profession" of pain medicine to the "business" of pain medicine. ${ }^{4}$ This series featured a number of highly critical articles, including examinations of the health insurance industry's refusal to cover interdisciplinary pain management programs ${ }^{5}$ the corporatization of American pain management and the resulting benefits to certain special interests and concomitant increases in disparities in pain care, ${ }^{6}$ physician complicity in the transformation of pain medicine from a profession to a business, ${ }^{7}$ the increase in pain management spending without any evidence of improved patient outcomes, ${ }^{8}$ the overutilization of interventional procedures and spine surgery by physicians who have "questionable" relationships with industry, ${ }^{9}$ conflict of interest relating to industry and its impact on pain education, ${ }^{10}$ and our failure to adequately address the ethical dilemmas that have been plaguing pain medicine for centuries. ${ }^{11}$ Although these articles, written by luminaries in the field, provided extremely entertaining (yet disturbing) reading, I question whether they had a significant impact on the ethical imbroglio that was (and still is) American pain medicine.

Irrespective, in a quixotic fashion, I persisted. Subsequent articles and textbook chapters included an examination of problems in pain management disparities research, ${ }^{12}$ the ethical imperative of balancing continuing medical education and conflicts in pain medicine, ${ }^{13}$ the role of inadequate workers compensation systems in perpetuating pain and disability, ${ }^{14}$ the lack of an evidence basis for mandated use of (expensive) electronic medical record systems in palliative and hospice medicine,${ }^{15}$ an exposé on medical marijuana dispensaries that make absurd amounts of money without carrying products that are particularly medical, ${ }^{16}$ the perpetuation of the American opioid 
crisis by the health insurance industry's concern solely for cost-containment and profitability, ${ }^{17}$ automobile insurance carriers' refusal to pay for psychological injuries sustained in motor vehicle accidents - thereby perpetuating physical and psychological suffering, ${ }^{18}$ and the American media's desire to "sell print" rather than providing an unbiased account of the many benefits as well as the obvious potential harms of opioid analgesics. ${ }^{19}$

Does anyone recognize a theme here? I have been convinced - and thoroughly so - that the quality of American pain medicine is severely compromised by the "evils" of capitalism. Due to the commodification of the American pain care system, patients have become "fungible". Physicians treating pain in the United States had become so frustrated by our system that they had all given up hope and were treating pain medicine like any other business. Or so I thought.

Last week, I had the opportunity to visit an organization in Massachusetts, Boston PainCare. A colleague had recommended that I meet with the physician owners of this pain clinic in order to discuss future possibilities for collaborative research. What I learned about their organization and commitment to the highest quality pain care and research frankly amazed me, to the extent that I felt compelled to write this editorial about what they are doing for their patients, and hopefully for the paradigm through which pain is treated in the United States. As one of their owners stated, "Like any business model our clinic needs to be profitable, but our focus is not on maximizing revenue at the expense of patient care". Quality of care is clearly the primary concern of these physicians - which I posit is sadly an anomaly in American pain medicine.

Boston PainCare was founded in 2007 by six anesthesiologists who had been treating patients in a hospital setting. Their initial goal remains their goal today, ie, to treat people suffering from pain from a patient-centric model that embraces functional and behavioral interventions as the core of its treatment approach. This is of great importance in the current climate of pain medicine, in which patients have been lost in "a sea of drugs and procedures" 20 for too many years. Since the organization's inception, it has grown substantially, as the partners have the wisdom to recognize that the discipline of anesthesiology - while an important component of pain care - is not sufficient to meet all of the complex biopsychosocial needs of patients suffering from the disease of chronic pain. This evolution in thinking is reflected in their approach to the use of interventional treatments. While Boston PainCare performs procedures in its own onsite ambulatory surgery center, they strongly reject the American pain medicine "block-shop" mentality in which too many injections are provided without adequate empirical evidence. ${ }^{21}$ Instead, these procedures are viewed as adjunctive therapies used to facilitate what they see as the central mission of pain treatment, namely the improvement of a patient's quality of life through the recovery of meaningful functioning (independence in self-care, social reengagement, vocational activities) and the replacement of maladaptive behaviors with adaptive coping strategies.

As the founding partners at Boston PainCare recognized that many of the patients who were referred to them were suffering from intractable headache pain, they brought a world-renowned neurologist/headache specialist into their facility to develop a specialized Headache Institute.

Additionally, given the body of research supporting the reciprocal and bidirectional relationship between chronic pain and impaired sleep, ${ }^{22}$ Boston PainCare opened an in-house Sleep Center in 2009, with that program receiving American Academy of Sleep Medicine accreditation. To the best of my knowledge, this is the only in-house accredited sleep center in a pain management facility in the United States. Given the organization's emphasis on quality, it is not surprising that the Sleep Center is led by a physician who is board-certified in Sleep Medicine.

Despite being founded by anesthesiologists, this unique group of clinicians recognizes that chronic pain needs to be treated not only biopsychosocially, but perhaps even from a sociopsychobiological model ${ }^{23}$ that emphasizes functional restoration through an interdisciplinary pain management program as well as the imperative of evidence-based behavioral approaches to chronic pain. Accordingly, the treatment team at Boston Pain Care includes four doctoral-level psychologists, all of whom have availed themselves of post doctoral training in pain management. Additionally, patients thought to potentially benefit from complementary and alternative medicine approaches are provided with such, with a chiropractor also included on the facility's interdisciplinary team. Nutrition is also considered an important part of treatment, which is supported by recent literature. ${ }^{24}$ Boston PainCare's staff includes four Registered Nurses and three Nurse Practitioners, who provide a wide range of clinical, educational, and administrative services. Their interdisciplinary functional restoration program staff, of course, includes a physical therapist. As is a problem throughout the vast majority of the United States, ${ }^{25}$ the insurance reimbursement climate in Massachusetts has made it a challenge to grow their interdisciplinary pain management program to the degree that the team would find optimal. Accordingly, 
the facility attempts to make all treatment that it provides as interdisciplinary as possible through regularly scheduled team meetings as well as frequent informal communication between members of the represented disciplines.

Boston PainCare's stated mission is the creation of a sustainable and scalable interdisciplinary treatment model capable of providing high quality care to an often poorly served patient population while reducing the adverse economic and societal consequences associated with the fractionated, unimodal and non purposeful treatment approaches commonly employed by the majority of pain care providers. ${ }^{26}$ Critical to this process is the development of their customized electronic health record system (NextGen platform), which allows for the identification and tracking of common treatment goals used by all disciplines in the development of individualized treatment plans. Individual and aggregated patient data extracted from their electronic health record system are also used for the monitoring of progress toward each patient's treatment goals as well as for the development of best practice approaches. As important, their use of information technologies allows them to incorporate cost, safety, and efficacy data into the creation of the clinic's treatment guidelines, such as the center's tiered pharmacy protocol that allows their clinicians to improve outcomes while reducing overall treatment costs.

Much has been written regarding the deleterious impact of the "war on opioids" on patients suffering from chronic pain. ${ }^{27-32}$ Recent prescribing guidelines, disingenuously identifying themselves as voluntary, ${ }^{33,34}$ have had a clear "chilling effect", resulting in many physicians choosing to exclude opioid analgesics from their pain management armamentaria. ${ }^{35}$ The anti-opioid climate in Massachusetts has been particularly pernicious, with a new bill limiting opioid prescriptions providing evidence of such. ${ }^{36}$ Irrespective, the physicians at Boston PainCare prescribe opioids to well-selected patients for whom there exist no other viable options. This is not to suggest that these providers are "pro-opioid"; in fact, much of their clinical work and research involves tapering patients for whom opioids are not appropriate from these medications. More so, they feel an obligation as pain specialists to not only reduce the adverse consequences of irresponsible opioid prescriptive habits but to also protect the appropriate access to these drugs through the practice and promotion of rational opioid treatment, which certainly involves aggressive risk mitigation. Patients being considered for opioid therapy undergo extensive psychological and functional evaluations prior to prescription. This approach was endorsed through a systematic review of guidelines for opioid prescribing that was conducted when guidelines were evidence-based rather than biased and consensus-based. ${ }^{37}$ Additionally, the Boston PainCare Medication Management Program is not run in a one size fits all manner. For example, team members meet on a weekly basis to review all new patient evaluations to determine the appropriateness of medication treatment. Patients accepted for enrollment are then placed into one of five care plan tracts by team decision, each of which offers varying levels of medical and behavioral health services to best meet the needs of each patient. Prescribing practices are supported by the presence of a doctoral-level pharmacist who provides chart reviews and pharmacological consultations for all patients undergoing medication treatment as well as monitoring of the center's rational prescribing program. While the rates of urine drug testing among physicians prescribing opioids in the United States are woefully low, with as few as $7 \%$ of patients receiving chronic opioid therapy determined at baseline measurement to undergo urine drug testing,,$^{38}$ all patients receiving opioids at Boston PainCare undergo routine urine drug testing. This process is made seamless by the inclusion of a medical technologist on staff and an in-house toxicology laboratory that allows for the review of drug testing data prior to the dispensing of opioid prescriptions. Indicative of the effectiveness of the overall approach to opioid treatment at Boston PainCare, the rate of occurrence of reported aberrant urine drug test results at their center $(7.6 \%)^{39}$ is significantly lower than those commonly cited in medical literature $(13 \%-40 \%){ }^{40}$ Furthermore, the treatment team at Boston Pain Care is unaware of any opioid overdose deaths since the facility's inception 9 years ago.

Finally, the medical staff at Boston Pain Care conducts and publishes scientific research on what constitutes effective pain management, with six manuscripts accepted over the past 3 years..$^{39,41-45}$ Additionally, the center has forged collaborative research relationships with both Tufts University and Massachusetts General Hospital, and currently have three manuscripts in preparation involving clinical outcomes data extracted from the more than 8,000 patients in their customized health records database. This is extremely important, as the days of the scientist-practitioner model of pain management seem to have become a thing of the past, with the disconnect between academicians and clinicians in pain medicine and its implications addressed in the literature. ${ }^{46}$

In summary, there is much that is wrong with American pain medicine, and I have learned that writing myriad articles merely exposing these problems does not necessarily remedy 
them. My recent visit to Boston PainCare, however, was both elucidating and encouraging. The interdisciplinary management of chronic pain at this high level was typically only seen at teaching institutions in the United States; however, as John Loeser noted almost a decade ago, even in academic institutions, "revenue generation is the major determinant of what services the institution will offer". ${ }^{47}$ Such an attitude is clearly not the guiding force behind Boston PainCare. This is one of the rare American pain treatment facilities that does it right, and the owners and their staff are aware of the excellence that they provide. However, rather than merely resting on their laurels, the leadership of this organization is dedicated to changing the paradigm through which chronic pain is treated not only on a local level, but nationally as well. Given my own burning desire to see a paradigmatic revision in pain care, my hope is that this brief discussion of the successful Boston PainCare model will serve to inspire other private and public facilities worldwide to closely examine their policies, procedures, and motivations, and to become a part of the solution rather than remaining a contributor to the problem of purely profit-motivated (and consequently inadequate) pain management.

\section{Disclosure}

The author reports no conflicts of interest in this work.

\section{References}

1. Giordano J, Schatman, ME. An ethical analysis of crisis in chronic pain care: facts, issues and problems in pain medicine; Part I. Pain Physician. 2008;11(4):483-490.

2. Giordano J, Schatman ME. A crisis in chronic pain care: an ethical analysis. Part two: proposed structure and function of an ethics of pain medicine. Pain Physician. 2008;11(5):589-595.

3. Giordano J, Schatman ME. A crisis in chronic pain care: an ethical analysis. Part three: toward an integrative, multi-disciplinary pain medicine built around the needs of the patient. Pain Physician. 2008;11:771-784.

4. Schatman ME, Lebovits AH. On the transformation of the "profession" of pain medicine to the "business" of pain medicine: an introduction to a special series. Pain Med. 2011;12(3):403-405.

5. Schatman ME. The role of the health insurance industry in perpetuating suboptimal pain management. Pain Med. 2011;12(3):415-426.

6. Meghani SH. Corporatization of pain medicine: implications for widening pain care disparities. Pain Med. 2011;12(4):634-644.

7. Lebovits A. Maintaining professionalism in today's business environment: ethical challenges for the pain medicine specialist. Pain Med. 2012;13:1152-1161.

8. Taylor ML. The impact of the "business" of pain medicine on patient care. Pain Med. 2011;12(5):763-772.

9. Perret D, Rosen C. A physician-driven solution - the Association for Medical Ethics, the Physician Payment Sunshine Act, and ethical challenges in pain medicine. Pain Med. 2011;12(9):1361-1375.

10. Schofferman J. The medical-industrial complex, professional medical associations, and continuing medical education. Pain Med. 2011; 12(12):1713-1719.

11. Kulich R, Loeser JD. The business of pain medicine: the present mirrors antiquity. Pain Med. 2011;12(7):1063-1075.
12. Campbell LC, Robinson K, Meghani SH, Vallerand A, Schatman M, Sonty N. Challenges and opportunities in pain management disparities research: implications for clinical practice, advocacy and policy. J Pain. 2012;13(7):611-619.

13. Schatman ME. Balancing continuing medical education and conflict of interests in pain medicine: an ethical imperative. Pain Med. Network 2012;27:10-11.

14. Schatman ME. Workers' compensation and its potential for perpetuation of disability. In: Gatchel RJ, Schultz I, editors. Handbook of Occupational Health and Wellness. New York: Springer; 2013:341-361.

15. Carter GT, Schatman ME. What is the evidence base for electronic medical records improving quality in hospice and palliative medicine? Am J Hosp Palliat Med. 2014;31(7):697-698.

16. Schatman ME. Medical marijuana: the state of the science. Medscape Neurology 2015. Available from: http://www.medscape.com/view article/839155. Accessed June 15, 2016.

17. Schatman ME, Webster LR. The health insurance industry: perpetuating the opioid crisis through policies of cost-containment and profitability. J Pain Res. 2015;8:153-158.

18. Schatman ME, Thoman JL. Valid psychological injury claims: respecting the needs of survivors. Psychological Injury and Law. 2015;8:311-322.

19. Schatman ME. The American chronic pain crisis and the media: about time to get it right? J Pain Res. 2015;8:885-887.

20. Chapman SL. Chronic pain rehabilitation: lost in a sea of drugs and procedures? Am Pain Soc Bull. 2000;10.

21. Knezevic NN, Lissounov A, Candido KD. Do we have an alternative to transforaminal injections to provide safe and effective lumbar epidural steroid injections to our patients while minimizing the burden to the healthcare system? Anesthesiology. 2016;124:239-241.

22. Cheatle MD, Foster S, Pinkett A, Lesneski M, Qu D, Dhingra L. Assessing and managing sleep disturbance in patients with chronic pain. Anesthesiol Clin. 2016;34(2):379-393.

23. Carr DB, Bradshaw YS. Time to Flip the Pain Curriculum? Anesthesiology. 2014;120:12-14.

24. De Grigorio M, Muscoli C, Schatman M, et al. Combining pain therapy with lifestyle: the role of personalized nutrition and nutritional supplements according to the SIMPAR FYD (Feed Your Destiny) approach. $J$ Pain Res. In press 2016.

25. Schatman ME. Interdisciplinary chronic pain management: international perspectives. Pain Clin Updates. 2012;20(7):1-5.

26. Vasudevan S. Multidisciplinary Management of Chronic Pain: A Practical Guide for Clinicians. Cham, Switzerland: Springer International Press; 2015.

27. Goldberg DS. On the erroneous conflation of opiophobia and the undertreatment of pain. Am J Bioeth. 2010;10(11):20-22.

28. Reed MD. The balance between effective opioid-based pain management and patient safety: can it be achieved? J Pediatr Pharmacol Ther. 2013;18(4):264-268.

29. Schatman ME, Darnall BD. A practical and ethical solution to the opioid scheduling conundrum. J Pain Res. 2014;7:1-3.

30. Atkinson TJ, Schatman ME, Fudin J. The damage done by the war on opioids: the pendulum has swung too far. J Pain Res. 2014;7:265-268.

31. Schecter NL. Pediatric pain management and opioids: the baby and the bathwater. JAMA Pediatr. 2014;168(11):987-988.

32. Dineen KK, Dubois JM. Between a rock and a hard place: can physicians prescribe opioids to treat pain adequately while avoiding legal sanction? Am J Law Med. 2016;42:7-52.

33. Washington State Agency Medical Directors' Group (AMDG) in collaboration with an Expert Advisory Panel, Actively Practicing Providers, Public Stakeholders, and Senior State Officials. Interagency Guideline on Prescribing Opioids for Pain, 2015. Available from: http://www. agencymeddirectors.wa.gov/Files/2015AMDGOpioidGuideline.pdf. Accessed June 11, 2016.

34. Dowell D, Haegerich TM, Chou R. CDC Guideline for Prescribing Opioids for Chronic Pain — United States, 2016. JAMA. 2016;315(15): 1624-1645. 
35. Anson P. Death rate from painkiller overdoses drops in Washington State. National Pain Report [webpage on the Internet]. Jan 28, 2013. Available from: http://nationalpainreport.com/death-rate-from-painkiller-overdosesdrops-in-washington-state-8818418.html. Accessed June 11, 2016.

36. Miller J. Governor Baker signs opioid bill. Boston Globe, March 14, 2016. Available from https://www.bostonglobe.com/metro/2016/03/14/ baker-due-sign-opioid-bill-monday/EYWh7oJXvKCRguHErxrWhI/ story.html. Accessed June 15, 2016.

37. Nuckols TK, Anderson L, Popescu I, et al. Opioid prescribing: a systematic review and critical appraisal of guidelines for chronic pain. Ann Intern Med. 2014;160(1):38-47.

38. Turner JA, Saunders K, Shortreed SM, et al. Chronic opioid therapy risk reduction initiative: impact on urine drug testing rates and results. J Gen Intern Med. 2014;29(2):305-311.

39. Weed V, Abdulaziz S, Wawrzyniak KM, DiBenedetto DJ, Kulich RJ, Porter R. Impact of urine drug toxicology (UDT) frequency on uncovering aberrant behaviors with chronic opioid therapy: implications of delay in time of discovery. Presented at the 31st Annual Meeting of the American Academy of Pain Medicine, Washington D.C., March, 2015.

40. Fishbain DA, Cole B, Lewis J, Rosomoff HL, Rosomodd RS. What percentage of chronic nonmalignant pain patients exposed to chronic opioid analgesic therapy develop abuse/addiction and/or aberrant drug-related behaviors? A structured evidence-based review. Pain Med. 2008;9(4):444-459.

41. Porter R, DiBenedetto DJ, Silk L, Estrada-Lyder MJ, Harrington C, Bajwa Z. Marijuana use predicts future aberrant behaviors in patients receiving opioids for chronic nonmalignant pain. Presented at the 29th Annual Meeting of the Academy of Pain Medicine, Fort Lauderdale, FL, April, 2013.
42. DiBenedetto DJ, Porter R, Harris-David L, Estrada-Lyder MJ, Silk L, Brogan J, Bajwa Z. Predictors for success in the treatment of aberrant medication abuse behaviors with cognitive behavioral therapy. Presented at the 29th Annual Meeting of the American Academy of Pain Medicine, Fort Lauderdale, FL, April, 2013.

43. DiBenedetto DJ, Porter R, Estrada-Lyder MJ, et al. Opioid dose reduction does not qorsen pain scores, perceived functional abilities or aberrant drug behaviors in patients on high-dose opioids. Presented at the 30th Annual Meeting of the American Academy of Pain Medicine, Phoenix, AZ, March, 2014.

44. Stone MT, DiBenedetto DJ, Wawrzyniak KM, Kulich RJ, Porter R. Targeting prescribers' behavior in the effort to reduce patients with chronic pain on high-dose opioid therapy: the impact of clinicianfocused, low-burden administrative interventions on patients' opioid dose. Presented at the 31st Annual Meeting of the American Academy of Pain Medicine, Washington D.C., March, 2015.

45. Weed V, Finkelman M, Wawrzyniak KM, Kulich RJ, Myrta E, DiBenedetto DJ. The use of the World Health Organization Disability Assessment Schedule (WHODAS 2.0) in a chronic pain population: the importance of functional assessments in the context of opioid risk evaluations. Presented at the 35th Annual Scientific Meeting of the American Pain Society, Austin, TX, May, 2016.

46. Giordano J, Schatman ME. Pain Medicine from "bench to bedside": bridging the disconnect(s) between research and clinical care. J Healthc Sci Humanit. 2011;1:22-41.

47. Loeser JD. Foreword. In: Schatman ME, Campbell A (editors). Chronic Pain Management: Guidelines for Multidisciplinary Program Development. New York: Informa Healthcare; 2007:iii-iv.

Dove Medical Press encourages responsible, free and frank academic debate. The content of the Journal of Pain Research 'Editorial' section does not necessarily represent the views of Dove Medical Press, its officers, agents, employees, related entities or the Journal of Pain Research editors. While all reasonable steps have been taken to confirm the content of each Editorial, Dove Medical Press accepts no liability in respect of the content of any Editorial, nor is it responsible for the content and accuracy of any Editorial.

\section{Journal of Pain Research}

\section{Publish your work in this journal}

The Journal of Pain Research is an international, peer reviewed, open access, online journal that welcomes laboratory and clinical findings in the fields of pain research and the prevention and management of pain. Original research, reviews, symposium reports, hypothesis formation and commentaries are all considered for publication.

\section{Dovepress}

The manuscript management system is completely online and includes a very quick and fair peer-review system, which is all easy to use. Visit http://www.dovepress.com/testimonials.php to read real quotes from published authors. 